\title{
Experimental study of verbal association learning in patients with severe dysphasia
}

\author{
MARIA WYKE \\ From the Neurosurgical Unit, National Hospital, Maida Vale, London
}

Meaningless syllables (nonsense syllables) have frequently been used to study learning. Each nonsense syllable usually consists of three letters beginning and ending with a consonant and having a vowel in the middle. For a long time, interest has been directed to the possible association with words elicited by different nonsense syllables and various studies have been carried out (Glaze, 1928; Hull, 1933; Archer, 1960; Noble, 1961; Chang and Shepard, 1964) in order to 'calibrate' nonsense syllables according to their 'association value', that is to say, according to the ease with which they suggest familiar words. Several such lists have been compiled: the degree of association value usually varies from $100 \%$, i.e., syllables that all subjects report as bringing forth associations with a particular word, to $0 \%$ i.e., syllables that all subjects report as not bringing forth any word association.

It has been found (Underwood and Schulz, 1960) that the ease with which a list of nonsense syllables is learned depends upon the ease with which associations with 'meaningful material' are made; the higher the meaningfulness, the faster the learning.

Conversely, by measuring the speed of learning lists of nonsense syllables of known association value, it is possible to make inferences about the readiness with which an individual can bring forth related verbal associations.

In a previous study (Wyke, 1962) it was found that it is easier to elicit correct verbal responses from dysphasic patients when the possible choice of response words was restricted by the stimulus situation than when this restriction was less stringent. It was then suggested that this might be the result of a basic breakdown of association of ideas rather than a simple alteration of verbal habits.

In the present paper an attempt is made to deal with this problem by examining the ability of patients with severe dysphasia to learn calibrated nonsense syllables as compared with the performance of patients with normal verbal functions. The purpose of the study is to ascertain the extent to which association processes are altered in patients with severe language defects.
SUBJECTS

The experimental subjects were 16 patients with the neurological disorders shown in Table I. Eight of these were dysphasic and a control group of eight patients had no dysphasia. Details of the language defects are shown

\begin{tabular}{|c|c|c|c|c|}
\hline \multirow[b]{2}{*}{ Group } & \multicolumn{4}{|c|}{$\begin{array}{l}\text { TABLE I } \\
\text { CASE DATA }\end{array}$} \\
\hline & Patient & Age & Occupation & Diagnosis \\
\hline \multirow[t]{8}{*}{ Dysphasic } & F.E. & 60 & $\begin{array}{l}\text { Staff } \\
\text { manager }\end{array}$ & Cerebral thrombosis \\
\hline & B.J. & 43 & $\begin{array}{l}\text { Printer's } \\
\text { assistant }\end{array}$ & Cerebral vascular accident \\
\hline & M.M. & 36 & Book-keeper & $\begin{array}{l}\text { Post-operative cerebral em- } \\
\text { bolism }\end{array}$ \\
\hline & P.C. & 60 & Statistician & $\begin{array}{l}\text { Ligation anterior carotid } \\
\text { artery for aneurysm }\end{array}$ \\
\hline & L.A. & 37 & Driver & $\begin{array}{l}\text { Post-operative thrombosis } \\
\text { middle cerebral artery }\end{array}$ \\
\hline & S.H. & 49 & $\begin{array}{l}\text { Service } \\
\text { manager }\end{array}$ & $\begin{array}{l}\text { Cerebral embolism follow- } \\
\text { ing aortic stenosis }\end{array}$ \\
\hline & A.E. & 47 & $\begin{array}{l}\text { Sheet metal } \\
\text { worker }\end{array}$ & $\begin{array}{l}\text { Thrombosis internal caro- } \\
\text { tid artery }\end{array}$ \\
\hline & C.H. & 63 & Engineer & Cerebral vascular accident \\
\hline \multirow[t]{6}{*}{ Control } & $\begin{array}{l}\text { N.J. } \\
\text { K.W. }\end{array}$ & $\begin{array}{l}42 \\
57\end{array}$ & $\begin{array}{l}\text { Clerk } \\
\text { Printer }\end{array}$ & $\begin{array}{l}\text { Disseminated sclerosis } \\
\text { Cerebral vascular accident } \\
\text { (non-dominant hemisphere) }\end{array}$ \\
\hline & J.K. & 51 & Driver & Disseminated sclerosis \\
\hline & G.P. & 35 & Postman & $\begin{array}{l}\text { Seizures (increased left side } \\
\text { reflexes) }\end{array}$ \\
\hline & $\begin{array}{l}\text { L.L. } \\
\text { J.R. }\end{array}$ & $\begin{array}{l}53 \\
54\end{array}$ & $\begin{array}{l}\text { Builder } \\
\text { Engineer }\end{array}$ & $\begin{array}{l}\text { Biparietal meningioma } \\
\text { Disseminated sclerosis }\end{array}$ \\
\hline & A.D. & 48 & Clerk & $\begin{array}{l}\text { Left hemiparesis (undiag- } \\
\text { nosed) }\end{array}$ \\
\hline & W.R. & 65 & Driver & Cervical disc degeneration \\
\hline
\end{tabular}

in Table II. These dysphasic patients also showed defects of reading and writing. All of them, however, were able to copy written material as well as being able to match printed words with corresponding pictures.

The mean duration of the illness in the dysphasic group was three years (range two to four years). All but one had attended a speech therapy clinic for at least one year and their language defects were considered to be stable. The control group was selected to be within the same age range as the experimental group. Both groups had similar intellectual abilities, as defined by the performance tests of the Wechsler adult intelligence scale. The results of these tests are shown in Table III. 
TABLE II

LANGUAGE DEFECTS IN DYSPHASIC GROUP

\begin{tabular}{ccc} 
Patient & Expression & Comprehension \\
\hline F.H. & +++ & ++ \\
B.J. & ++ & - \\
M.M. & +++ & ++ \\
P.C. & +++ & + \\
L.A. & +++ & + \\
S.H. & ++ & + \\
A.E. & ++ & +
\end{tabular}

- None, + Moderate, ++ Severe, +++ Very severe

\section{TABLE III}

SCORES OF DYSPHASIC AND CONTROL GROUPS ON WECHSLER ADULT INTELLIGENCE PERFORMANCE SCALE

Group Patient $\begin{array}{lll}\text { Test } & \begin{array}{l}\text { Digit } \\ \text { Symbol }\end{array} \begin{array}{l}\text { Picture Block } \\ \text { Com- } \\ \text { pletion }\end{array} & \begin{array}{l}\text { Picture } \\ \text { Design }\end{array} \begin{array}{l}\text { Arrange- } \\ \text { ment }\end{array}\end{array}$

\begin{tabular}{rlrrrrrr}
\hline Dysphasic F.E. & 9 & 10 & 11 & 3 & 7 & 91 \\
B.J. & 6 & 9 & 6 & 10 & 9 & 93 \\
M.M. & 10 & 14 & 18 & 12 & 14 & 129 \\
P.C. & 12 & 10 & 17 & 10 & 12 & 116 \\
L.A. & 6 & 13 & 10 & 10 & 7 & 99 \\
S.H. & 8 & 10 & 13 & 13 & 9 & 109 \\
A.E. & 6 & 10 & 13 & 14 & 11 & 113 \\
Control & C.H. & 7 & 10 & 11 & 12 & 8 & 102 \\
N.J. & 11 & 13 & 11 & 12 & 11 & 110 \\
& K.W. & 15 & 12 & 13 & 10 & 11 & 112 \\
J.K. & 8 & 10 & 12 & 9 & 11 & 104 \\
G.P. & 13 & 7 & 11 & 10 & - & 101 \\
L.L. & 9 & 13 & 13 & 13 & - & 112 \\
J.R. & 10 & 10 & 12 & 14 & - & 109 \\
A.D. & 14 & 12 & 15 & 9 & 12 & 114 \\
W.R. & 8 & 14 & 10 & 11 & 7 & 98
\end{tabular}

'In the final calculation of the dysphasic patients' I.Q., the subtest of digit symbol has been omitted, because due to their neurological disabilities seven patients used the left hand (non-dominant) for writing, slowing their performance.

\section{TEST MATERIAL}

The test material consisted of six cards, each having threeletter nonsense syllables printed on it. The syllables were chosen from Glaze lists (modified by Hilgard, 1951) which are graded according to their degree of association value. Each card contained five nonsense syllables selected from the $100,80,60,40,20$, and $0 \%$ association value lists respectively. The nonsense syllables were selected at random, subject to the restriction that no particular consonant would appear more than twice on a card and that not all the vowels would be present within the same card. Thus, on each card there were four different vowels with one vowel repeated once. This was to prevent guessing based on a belief that the five vowels were present within each list. In the case of lists with high association value care was taken to avoid resemblance to meaningful verbal sequences.

Two more cards were used, one with five three-letter words constructed similarly to the nonsense syllables, i.e., beginning and ending with a consonant and having a vowel in the middle, and one with five simple geometrical designs.

PROCEDURE

A test card was presented to the subject and he was asked to copy the printed list. The test card and the subject's copy were removed from his sight and he was then asked to re-write in the same order what he had just copied. If he was not able to recall the contents of the card correctly, he was shown the card again and asked to copy and then recall it once more. This procedure was repeated until he was able to master the contents of the card to the criterion of three successive reproductions.

The cards with nonsense syllables and also those containing the words were presented first, followed by the card with the designs. The order of presentation of the test cards with the nonsense syllables and that with the words were randomized for each subject. All subjects learned the eight cards.

Testing was carried out in three to four sessions with the control group and in four to five sessions with the dysphasic group, each session lasting about an hour. The subjects were allowed 10-minute rests between lists. This was done in order to avoid the effects of proactive inhibition, i.e., the influence of prior learning on present learning (Underwood, 1957).

\section{RESULTS}

The number of trials needed by each subject to learn the list of nonsense syllables, words, and designs for both the dysphasic group and the control group is shown in Table IV. The mean number of trials needed by each group to learn to find criteria for the lists of nonsense syllables of different association value is graphically displayed in Fig. 1. For con-

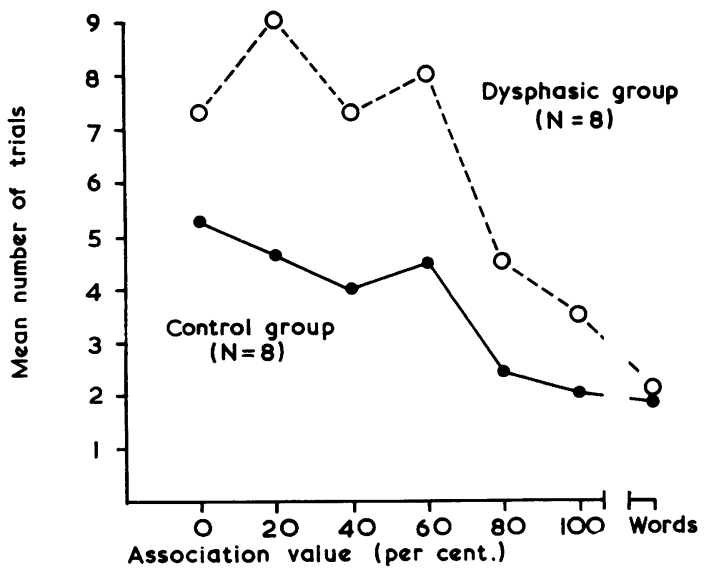

FIG. 1. Mean number of trials needed by dysphasics and non-dysphasic groups to learn to reach criteria. 
TABLE IV

NUMBER OF TRIALS NEEDED BY DYSPHASICS AND CONTROL SUBJECTS TO REACH CRITERIA

Control Group

F.E. B.J. M.M. P.C. L.A. S.H. A.E. C.H.

N.J. K.W. J.K. G.P. L.L. J.R. A.D. W.R.

\begin{tabular}{lrrrr}
\hline $100 \%$ Association value & 3 & 3 & 3 & 3 \\
$80 \%$ & 6 & 4 & 6 & 5 \\
$60 \%$ & 9 & 10 & 7 & 7 \\
$40 \%$ & 5 & 8 & 6 & 11 \\
$20 \%$ & 12 & 7 & 9 & 11 \\
$0 \%$ & 5 & 8 & 5 & 9 \\
Words & 2 & 3 & 3 & 1 \\
Designs & 3 & 4 & 2 & 5
\end{tabular}

Designs

6
5
10
11
9
11
2
3

Significant at ${ }^{1} 0.02,{ }^{2} 0.05,{ }^{3} 0.01$ level of confidence

venience of presentation the points of the graph have been joined together. This does not imply that the successive order of association value is thought to be a continuum.

Two different statistical analyses were performed. The Mann-Whitney $U$ test was used in order to compare the performance of the dysphasic and control groups at each level of association value. The same test was also applied to examine differences between the groups in their performance on the lists of words and designs.

Next, two-way analyses of variance were carried out to establish that differences in association value affected performance independently of differences between subjects. A summary of these analyses of variance is given in Table $\mathrm{V}$.

\section{TABLE V}

ANALYSES OF VARIANCE

\begin{tabular}{lrcr} 
Source of Variation & D.F. & Mean Square & \multicolumn{1}{c}{$F$} \\
\hline A Dysphasic Group & & & \\
Between subjects & 7 & $12 \cdot 1$ & $4 \cdot 7^{1}$ \\
Between association value & 5 & $36 \cdot 1$ & $14 \cdot 0^{2}$ \\
Rem. & 35 & $2 \cdot 6$ & \\
B Control Group & 7 & & \\
Between subjects & 5 & $13 \cdot 3$ & $5 \cdot 6^{2}$ \\
Between association value & 35 & $1 \cdot 4$ & $9 \cdot 2^{2}$ \\
Rem. & &
\end{tabular}

'Significant at 0.01 level

-Significant at 0.001 level

The results of the Mann-Whitney $U$ tests show that the learning performance of the dysphasic patients was inferior to that of the control group on five lists. In three lists there were no statistically significant differences, i.e., the list of words, the list of designs, and the list corresponding to $0 \%$ association value (see Table IV).

The results of the analyses of variance show that for both groups estimates of the variance attributable to differences in association value of the syllables, and to differences between subjects are significant. The greatest variance, however, arises from the differences between association value.

\section{ERRORS}

The numbers of errors made by the dysphasic group and the control group were also analysed. The criterion for error was the reproduction of a syllable different from the printed list. Changes in position within the list, or incomplete reproduction (i.e., when the subject wrote only one or two letters of the syllable) were not scored as errors.

The total number of errors made by the dysphasic group was larger than that of the control group, the number of errors increasing in the lists corresponding to $60 \%$ association value in both groups. Few errors were made by either group in the lists corresponding to 100 and $80 \%$ association value.

Some of the errors made by both groups consisted of changes into words; examples of these are the nonsense syllable 'foj' recalled as fog; the syllable 'fex' recalled as flex.

The number of changes to meaningful words was considerably larger in the control group than in the dysphasic group. Thus, out of 211 errors made by the dysphasic group in the six lists of nonsense syllables, there were only 16 errors of changes to words. In the control group out of a total number of 146 errors, 24 were changes to words. The $\chi^{2}$ value for this comparison is significant at the 0.01 level of confidence $\left(\chi^{2}=6 \cdot 80\right)$.

\section{DISCUSSION}

The findings in this study show that patients with dysphasia have greater difficulty in learning lists of nonsense syllables than non-dysphasic subjects. However, this difference is not statistically significant when nonsense syllables have no 'associative strength', as in the case of syllables of $0 \%$ association value. The results also show that there is no signicant difference between dysphasic and non-dysphasic subjects in the number of trials needed to learn a list of words or a series of simple designs. Further, the findings suggest that the difficulty encountered by dysphasic patients in learning lists of nonsense 
syllables is only present when learning depends on the ability to form an association with a particular word.

It seems reasonable to assume that in learning a list of nonsense syllables there are two main steps: first, the transformation of individual letters into a cohesive group of phonemes (this will apply whether the symbols are speech sounds or their graphic surrogates, i.e., letters in the present experiment); second, the association of a particular word to the nonsense syllables which serves as a stimulus. Thus, when a subject is presented with the stimulus syllable PIK, the first step in learning will be to bring these three letters $(P, I, K)$ into a cohesive group of phonemes (pIk). Subsequently, the retention of the syllable will depend on the readiness with which a subject can form a meaningful association. The meaningful link could be a simple transformation of the nonsense syllable into a three-letter word, or else the associative link could be derived from other words of which the nonsense syllable forms only a part.

If this is so, then slowness in learning may be due to three sorts of difficulty: (a) a general difficulty in learming; (b) a difficulty at the level of phonetic organization; (c) a difficulty in forming rapid word associations with a particular nonsense syllable.

It is pertinent to consider these different possibilities in the order in which they have been mentioned.

(a) Generalized difficulty in learning cannot be invoked as the explanation for the different results obtained from the dysphasic and non-dysphasic subjects. There was no significant difference between dysphasics and controls in learning lists of words, lists with no 'associative strength', or a series of simple designs.

(b) Nor does the explanation of this difference lie in the difficulty of transforming the individual letters into a cohesive group of phonemes. This is inferred from the fact that there was no evidence to suggest that the subjects were learning the individual letters rather than the syllables. If they had done so, there would have been no difference in the number of trials needed to learn the different lists, as all the lists were constructed in a similar manner having the same number and kind of letters differing only in the association value of the syllables. Yet, as can be seen in Fig. 1, the mean number of trials needed to learn the different lists varied considerably.

(c) Therefore the third possibility, difficulty in forming rapid meaningful association with a particular nonsense syllable, is a more likely explanation.

First, the results show that there is no significant difference between the two groups, in the number of trials needed to learn a list with no 'associative strength'. As it is known that these syllables possess no association value, the speed of learning is not likely to be facilitated by the ability to form meaningful associations. Second, results show no significant difference between the dysphasic and non-dysphasic subjects in learning words.

Words are per se meaningful symbols, therefore the speed of learning individual words need not necessarily depend upon the ability to form rapid associations with other words. Moreover, in the present experiment, associative processes in learning the list, rather than the individual words, were greatly minimized. There were only five three-letter words selected in such a way as to avoid similarity between the words and possible verbal sequences.

The hypothesis that the slowness with which dysphasic subjects learn nonsense syllables stems from their inability to form meaningful associations to the stimulus syllable is supported by the supplementary observations reported in this paper.

For example, the non-dysphasic subjects transformed nonsense syllables into words more frequently than the dysphasic subjects. This suggests that the use of meaningful links as mediating factors in verbal learning is more readily available to the non-dysphasic subject than it is to the dysphasic.

The observations reported here show that th $\vec{\Phi} \vec{v}$ breakdown of association processes in patients with dysphasia extends beyond that found in verbaq response such as in naming objects, responding to $\vec{\nabla}$ spoken stimulus words, or providing verbal response to visual stimuli (see Schuell and Jenkins, 1961 Wyke, 1962) to include other aspects of verbal beo haviour, i.e., learning and recall. Moreover, furthe evidence is provided for the suggestion that dysphasia is not merely a specific loss of expression and comprehension of speech but is a more fundamental verbal disorganization. It would appear that the breakdown of verbal ability is at the level of the more intricate semantic connexions.

It is important to point out that even in cases of severe dysphasia, as is the case in the present study, the semantic mediating processes that exist in normal verbal behaviour are not completely lost. Analysis of the results shows that the number of trials needed by the dysphasic subject to learn lists with high association value were smaller than those required to learn lists with low association value. This would suggest that the availability of meaningful connexions is reduced but not abolished. In this respect it is relevant to note that it has been pointed out (Jenkins, 1961) that the association processes mediating learning in normal subjects may not be invariable in their mode of operation, since they can be inhibited, facilitated, or interfered with by various activities of the subject. Whether the factors that inhibit association processes in normal subjects are 
similar to those in dysphasic subjects remains to be seen.

\section{SUMMARY}

An analysis of verbal association processes in learning nonsense syllables was undertaken in eight patients with dysphasia and eight patients with neurological disorders without dysphasia.

The pattern of learning shows that patients with dysphasia have greater difficulty in learning nonsense syllables than non-dysphasic patients, when learning depends upon the ability to form associations with a particular word. This suggests that the breakdown of association processes, which has been shown to occur when dysphasics are required to name objects and respond to spoken stimulus words, also accounts for the impairment of other aspects of language function, namely, verbal learning and recall.

Some theoretical implications of this finding are discussed.

I should like to thank Mr. V. Logue, Professor C. Oldfield, and Mr. M. Piercy for their advice, Miss E. Butfield, Principal of the West End School of Speech Therapy, for the evaluation of language defects in the dysphasic subjects, and the Paddington Group Hospital Committee for facilities provided. I am also grateful to Mr. A. Winfield, Linguistics Research Unit, Oxford, for statistical help.

The work was supported by a Medical Research Council grant.

\section{REFERENCES}

Archer, E. J. (1960). A re-evaluation of the meaningfulness of all possible CVC trigrams. Psychol. Monogr., 74, No. 10, [whole no. 497] pp. 1-23.

Chang, J. J., and Shepard, R. N. (1964). Meaningfulness in classification learning with pronounceable trigrams. J. verb. Learn. verb. Behav., 3, 85-90.

Glaze, J. A. (1928). The association value of nonsense syllables. J. genet. Psychol., 35, 255-267.

Hilgard, E. R. (1951). Methods and procedures in the study of learning. In Handbook of Experimental Psychology, edited by S. S. Stevens, pp. 517-567. Chapman \& Hall, London.

Hull, C. L. (1933). The meaningfulness of 320 selected nonsense syllables. Amer. J. Psychol., 45, 730-734.

Jenkins, J. J. (1961). Comments on Professor Goss's paper. In Verbal Learning and Verbal Behavior, edited by C. N. Cofer (Proceedings of a conference sponsored by the Office of Naval Research and New York University). McGraw-Hill, New York.

Noble, C. E. (1961). Measurement of association value (a) rated associations $\left(\mathrm{a}^{1}\right)$ and scaled meaningfulness $\left(\mathrm{m}^{1}\right)$ for the 2100 CVC combinations of the English alphabet. Psychol. Rev., 8, 487-521. (Monogr. suppl. 3-V8).

Schuell, H., and Jenkins, J. J. (1961). Reduction of vocabulary in aphasia. Brain, 84, 243-261.

Underwood, B. J. (1957). Interference and forgetting. Psychol. Rev., 64, 49-60.

—, and Schulz, R. W. (1960). Meaningfulness and Verbal Learning. Lippincott, Chicago.

Wyke, M. (1962). An experimental study of verbal association in dysphasic subjects. Brain, 85, 679-686.

\section{The February 1966 Issue}

\section{THE FEBRUARY 1966 ISSUE CONTAINS THE FOLLOWING PAPERS}

Differential effects on tonic and phasic reflex mechanisms produced by vibration of muscles in man P. DE GAIL, J. W. LANCE, and P. D. NEILSON

Digital nerve conduction in the carpal tunnel syndrome after mechanical stimulation of the finger J. G. MCLEOD

Enzyme histochemistry of skeletal muscle. Part III Neurogenic muscular atrophies VICTOR DUBOWITZ

Proximal spinal muscular atrophy MAURICE GROSS

Facial myokymia W. B. MATTHEWs

Changes due to age in internodal length in the sural nerve in man R. G. LASCELLES and P. K. THOMAS

Cerebellar degeneration with Hodgkin's disease L. HORWICH, P. H. BUXTON, and G. M. S. RYAN

Intellectual functions in patients with lateralized frontal tumours AARON SMITH
Epidemiological study of multiple sclerosis in Israel. Part II Multiple sclerosis and level of sanitation URI LEIBOWITZ, AARON ANTONOVSKY, JACK M. MEDALIE, HERBERT A. SMITH, LIPMAN HALPERN, and MILTON ALTER

Lesions of the spinal cord in polyradiculoneuropathy of unknown aetiology and a possible relationship with the Guillain-Barré syndrome WILLIAM I. ROSENBLUM, GLEB BUDZILOVICH, and IRWIN FEIGIN

Free acetylcholine in the cerebrospinal fluid after brain operations A. SAHAR

Two cases of localized hypertrophic neurofibrosis D. A. SIMPSON and M. FOWLER

Excretion of 5-hydroxyindolyl acetic acid (5HIAA) in migraine G. CURZON, PRUNELLA THEAKER, and B. PHILLIPS

Book reviews

Copies are still available and may be obtained from the PUBLISHING MANAGER, BRITISH MEDICAL ASSOCIATION, TAVISTOCK SQUARE, W.C.I., price 18s. 6D. 